\title{
DOCTRINA ARISTOTÉLICA DE LA IMPUTACIÓN*
}

\section{Planteamiento del problema}

Una de las facetas más interesantes de la filosofía moral del Estagirita es su doctrina de la imputación, término por cierto no aristotélico, ${ }^{1}$ pero que expresa mejor que cualquiera otro lo que el filósofo quiere decir cuando explica en qué casos un acto es atribuible a un sujeto $\mathrm{y}$, por consiguiente, hace que éste, según la cualidad pasitiva o negativa de su conducta, sea merecedor de alabanza o vituperio.

El pensamiento de Aristóteles en torno del problema de la imputatio es, en parte, antecedente y, en parte, complemento de su teoria de la justicia, aun

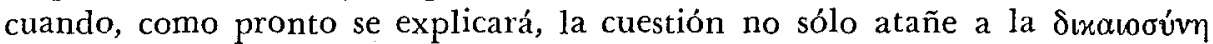
y a la ảoixía, sino a todas las formas manifestativas de las virtudes y los vicios. Pero como las enseñanzas del maestro del Liceo sobre la correcta atribución de alabanzas y censuras son especialmente referidas por él a los actos justos 'e injustos y a los casos en que los supuestos para imputar hechos delictuosos no se han realizado, esas enseñanzas constituyen un complemento importante de su doctrina de la justicia. Lo dicho permite entender por qué, después de un amplísimo estudio de la cuestión en los capítulos primero a quinto del Libro III, Aristóteles vuelve sobre el tema en el capítulo octavo del Libro $V$ de la Ética nicomaquea, y ello con el doble propósito de recor-

* Capítulo de un libro de próxima publicación.

I Según Richard Loening, Samuel Pufendorf fue quien introdujo como término técnico en la ciencia del derecho la voz improtatio, entendiendo por tal "los supuestos subjetivos para el castigo de los delitos" e imprimiendo al estudio de dichos supuestos el sello de la unidad sistemática. El autor de Le droit de la nature et des gens dio a su doctrina de la imputación una forma tan elaborada, que sus enseñanzas "se convirtieron, hasta llegar a Feuerbach, en el modelo seguido por toda la escuela iusnaturalista" ( $R$. Loening, Die Zurechnungslehre des Aristoteles, Jena, Verlag von Gustav Fischer, 1903, Vorwort, p. X). "Las acciones morales - escribe Pufendorf _ no son otra cosa que las acciones voluntarias del hombre, consideradas desde el punto de vista de la impritación de sus efectos en la vida comuin" (Le droit de la nature et des gens, Amsterdam, Chez Pierre de Coup, 1712 , Tome Premier, Liv. I, Chap. V, p. 68). En la siguiente página de la misma obra, Pufendorf sostiene que "la forma de las acciones morales consiste en la imputabilidad, si me atrevo a hablar asi, mediante la cual los efectos de una acción voluntaria pueden ser imputados al agente, considerados como algo que pertenece a éste en cuanto autor; sea que él físicamente haya producido por sí mismo esos efectos, sea que haya sido la causa de su existencia, inmediatamente provocada por otro". Sobre la doctrina imputativa de Pufendorf y la influencia que en ella ejerció Aristóteles véanse los capítulos segundo y sexto de la monografia de Hans Welzel titulada Die Naturrechtslehre Samuel Pufendorfs (La doctrina iusnaturalista de Samuel Pufendorf), Walter de Gruyter \& Co., Berlin, 1958. 
dar las conclusiones a que llegó en el Libro III y de aplicarlas al tópico de la justicia y la injusticia.

De la importancia que la teoría de la imputación tiene para él da buena prueba el hecho de que no sólo en la principal de sus tres Éticas, sino en la eudemia y en los Magna Moralia, dedique a esa teoría no pocos capítulos. ${ }^{2}$

Punto de partida de sus desarrollos, tanto en los dos citados libros de la Ética nicomaquea como en los que consagra al mismo argumento en sus otros tratados de filosofía moral, es el concepto de lo voluntario. Luego de resumir, en los capítulos sexto y séptimo del Libro $\mathrm{V}$ de aquella obra, los resultados a que llegó anteriormente, inicia el capítulo octavo con estas palabras: "Siendo justas e injustas las acciones dichas, una persona procede en forma justa o injusta cuando las realiza voluntariamente. . Pero cuando obra en forma involuntaria, ni comete injusticia ni obra con justicia, sino sólo por accidente, puesto que ejecuta acciones que sólo de modo concomitante son justas o injustas." 3

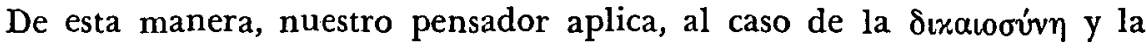
ảdxxía, el principio expuesto en el libro III de la Etica nicomaquea, según el cual el hombre sólo es responsable de las acciones que de él dependen o, en otras palabras, de las que ha realizado en forma voluntaria. ${ }^{4}$

Voluntariedad es el atributo que, según Aristóteles, permite aplicar a un comportamiento los predicados bueno o malo, justo o injusto, y referirlos al sujeto actuante. 5 Cuando sostenemos que una conducta es buena o mala no sólo la calificamos a ella, sino a quien, por haberla ejecutado, alabamos o censuramos.

"Refiriéndose la virtud a las pasiones y a las acciones, y recayendo sobre las voluntarias alabanzas y censuras, y sobre las involuntarias perdón y, en ocasiones, incluso piedad, probablemente sea necesario, a los que investigan acerca de la virtud, definir lo voluntario y lo involuntario, lo que también será útil a los legisladores al establecer los premios y los castigos." ${ }^{6}$

Del paso anterior se sigue: 1) que no sólo hay imputación de virtudes y vicios, sino, como consecuencia de la misma, también de alabanza y vituperio; 2) que estas formas de imputación no son de naturaleza juridica, en el sentido actual del término, sino de índole ética, aun cuando, como escribe nuestro filósofo, su estudio pueda ser útil a los legisladores al establecer los castigos y los premios.

2 Cfr. $M M$, Libro I, capítulos 9-19; $E E$, Libro II, capítulos 6-11.

$3 E N$, Libro V, capitulo octavo, 1135 a, 15-18.

$4 E N, 1111$ a, 22-24. Sobre el mismo principio: $E E, 1225 \mathrm{~b}, 3^{6-37} ; 1226 \mathrm{~b}, 17-19$.

$5 E N, 1101 \mathrm{~b}, 13^{-18} ; 1113 \mathrm{~b}, 3^{-14}$. Sobre este punto, Loening escribe: "El objeto propio de los juicios morales de valor está constituido por las' acciones humanas, pero no tanto en su carácter de aconteceres externos, sino en el que les corresponde como emanación y ejercicio de propiedades internas del hombre". Opus cit., p. 125.

( $E N, 1 \log \mathrm{b}, 3^{0-35}$. 
Respecto de ambas formas imputativas, lo que viene en cuestión, como efecto de los actos - dice Loening- son los juicios morales de alabanza y. censura o la exclusión de éstos, no la imputación de recompensas o de penas, ${ }^{7}$ si bien, como Aristóteles expresamente lo indica, conocer los supuestos que condicionan la procedencia o improcedencia de aquellos juicios en todo caso interesa y beneficia al legislador penal.

Debe subrayarse que el destinatario de las alabanzas y las censuras es siempre, a fin de cuentas, el hombre mismo, el hombre como un todo; y se le elogia o se le critica porque ha realizado tales o cuales acciones, sea que,

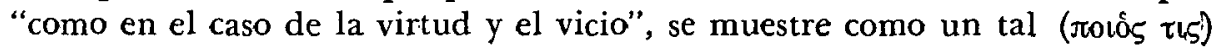
de quien semejantes acciones "permanentemente procederán", sea que sólo aparezca como autor de un acto determinado. 8

Tanto en el primero como en el segundo de estos casos, la imputabilidad o no imputabilidad dependen, según se ha dicho, de que el comportamiento que se juzga sea o no voluntario. Para determinar con rigor los supuestos de la correcta atribución de alabanzas y censuras, virtudes y vicios, tendremos, pues, que establecer ante todo cuándo puede y cuándo no puede afirmarse que una conducta es voluntaria.

\section{Lo voluntario y lo involuntario}

Siguiendo su costumbre de definir primeramente los términos negativos, Aristóteles inicia de este modo su análisis del tema: "Parecen ser involutarios los actos que se ejecutan por la fuerza y por ignorancia. Es forzado aquel acto cuyo origen es exterior, es decir, de tal índole que ni el agente ni el paciente aportan nada a su realización, como si el viento, $\mathbf{u}$ hombres que los tienen en su poder, los arrastraran a alguna parte." o

De esta cita podemos inferir que en lo voluntario deben darse dos elementos: 1) ha de ocurrir a sabiendas; y 2) libre de coacción.

$\mathrm{Si}$, en cambio, un acto se ejecuta por ignorancia ( $\left.\delta \iota^{\prime} \alpha{ }^{\gamma} \gamma v o t \alpha v\right) \mathrm{u}$ obedece a fuerza ajena ( $\beta i \alpha)$, habrá que darle el calificativo de involuntario (áxov́owov), ya que su causa ( $\alpha_{\varrho} \chi \eta \dot{)}$ es exterior al actuante. ${ }^{10}$

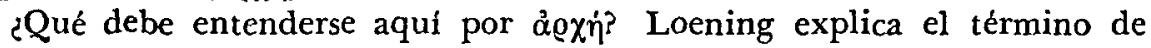
esta manera: "Dado que la acción aparece como un movimiento corporal,"

7 Loening, op. cit., p. 129.

8 Loening, op. cit., p. 268.

- $E N, 1109$ b, $35^{-1110}$ a, 4 .

10 En $E N, 1110 \mathrm{~b}, 15^{-17}$, refiriéndose Aristóteles a lo que obedece a fuerza ajena, expresa: "Forzado es aquello cuyo origen es exterior, y a lo que en nada contribuye el que sufrió la coacción". El mismo concepto es explicado así en $M M, 1188$ b, 7-9: "Siempre que la causa de que los hombres hagan algo contrario a su naturaleza o a su deseo esté fuera de ellos, diremos que se hallan forzados a hacer lo que hacen." En EE, 1224 a, 11-30, el Estagirita discute en qué casos puede el concepto de lo que obedece a fuerza externa aplicarse a los animales e, incluso, a lo inanimado.

11 Met., IV, 17, 1022, 7; EE, $1220 \mathrm{~b}, 27 ; E E, 1222 \mathrm{~b}, 28$. 
puede seguramente aceptarse que por ả@ $\chi \dot{\eta}$ hay que entender la causa que mueve a la acción (y no, como incorrectamente suele decirse, el principio) de ésta." La voluntariedad depende, pues, de que la acción tenga su causa en el actuante $o$, en otras palabras, "de que sea producida por la interioridad del mismo, no por una fuerza externa".12 Y ya se sabe que, para el

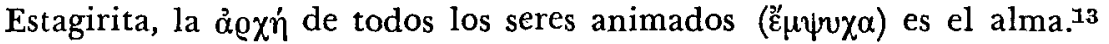

De acuerdo con la enseñanza aristotélica - prosigue Loening- "la única función psíquica capaz de provocar de modo inmediato movimientos corpóreos en el espacio o en la conducta es el deseo (ó motivo o el fundamento a que obedezca". ${ }^{4}$ Por ello, también, "el deseo que

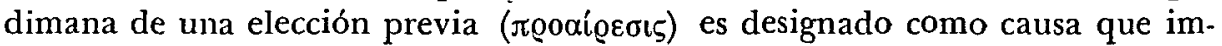
pele a la acción". ${ }^{15}$

Las ideas que, en torno de las nociones de lo voluntario y lo involuntario, expone Aristóteles en el Libro III, son resumidas de este modo por éi en el capítulo octavo del Libro V de la Ética nicomaquea: "Llamo voluntario, como arriba quedó dicho, lo que alguno hiciere, de lo que de él depende, sabiendo y no ignorando a quién lo hace, con qué lo hace y para qué lo hace. (Como, por ejemplo, cuando lesiona a otro con algo y en vista de algo, y ejecuta cada una de estas acciones no por accidente, ni hallándose forzado.) Si alguien, tomándonos la mano, hiere a otro, no podrá decirse que el acto es voluntario por no haber dependido de nosotros. Es posible que el herido sea el padre y que el que hiere crea que es otro hombre o alguno de los presentes, e ignore que se trata de su progenitor. De igual manera hay que distinguir respecto del motivo y de la acción considerada en su totalidad." 16

En este paso, el Estagirita define positivamente lo voluntario. Al escribir que "es voluntario lo que alguno hiciere, de lo que de él depende, sabiendo y no ignorando a quién lo hace, con qué lo hace y para qué lo hace", ${ }^{17}$

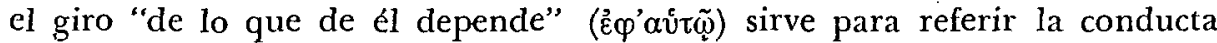
a la interioridad del actuante o, mejor dicho, a su voluntad. Sostener que una acción "depende de nosotros" equivale al aserto de que, ante la doble posibilidad de ejecutarla o de omitirla, deliberadamente optamos por la ejecución, lo que al propio tiempo implica que en nuestra mano estaba haber hecho lo contrario. Mas, como lo revela la segunda parte de la frase, para que una conducta sea voluntaria no basta que su ejecución dependa del actuante, ya que es necesario, asimismo, que el que obra lo haga a sabiendas

12 Loening, op. cit., p. 133 .

13 De anima, I, 3, 406 b, 24; Met., VIII, 2, $1046 \mathrm{~b}, 17$. Cfr. Loening, op. cit., pp. 134 y 135 .

14 Loening, op. cit., p. 134 .

15 Idem.

$16 E N, 1135$ a, 23-31.

$17 E N, 1135$ a, 23-25. 
y. con pleno conocimiento de las circunstancias de su obrar. Es preciso, para expresarlo de otro modo, que el sujeto sepa sobre quién recaerán las consecuencias de su comportamiento, de qué medios o instrumentos se vale para realizarlo y en vista de qué lo realiza. Por ello, lo que alguien ocasiona movido por una fuerza extraña (ejemplo del que hiere cuando otro más fuerte que él mueve su brazo), no depende del que sufre la coacción, sino de quien lo coacciona. ${ }^{18}$

De lo que Aristóteles asienta en 1135a, 28-30, colígese, igualmente, la posibilidad de que un hombre haga algo sabiendo con qué lo hace y en vista de qué lo hace (herir con una daga a un ladrón, verbigracia), pero, debido a otras circunstancias del acto (oscuridad, por ejemplo), hiera, no al ladrón, sino a su propio padre. Para emitir un juicio acerca de un proceder es, pues, indispensable "distinguir respecto del motivo y de la acción considerada en su totalidad". 19

Volviendo al tema de la justicia, Aristóteles aplica así las ideas expuestas por él en $E N$ 1135a, 24-31: "Suponiendo, por ejemplo, que alguien entregue involuntariamente un depósito, o lo restituya por temor, no podrá afirmarse que realiza acciones justas ni que obra justamente, salvo en forma accidental. Del mismo modo habrá que decir que quien no devuelve un depósito por hallarse forzado y obrar en forma involuntaria, sólo por accidente realiza un acto injusto o procede con injusticia." 20

\section{Concepto de acción mixta}

Después de establecer, en $1109 \mathrm{~b}, 35^{-1110 a, 1}$, el principio de que son involuntarias las acciones que obedecen a coacción o a ignorancia, Aristóteles escribe: "Se duda si son voluntarios o involuntarios los actos que se ejecutan por miedo a males mayores o por algo noble, como si un tirano, habiéndose apoderado de nuestros padres e hijos nos ordenara algo deshonroso, de hacer nosotros lo cual ellos se salvarían y, de no hacerlo, serían muertos. Algo semejante ocurre con lo que se lanza al mar en las tempestades. Pues, normalmente, nadie arroja la carga de buen grado, aun cuando, para su salvación y la de los demás, lo hagan todos los que están en su sano juicio." 21

En el sentir del Estagirita, semejantes acciones deben ser consideradas más como voluntarias que como involuntarias. La razón es que resultan

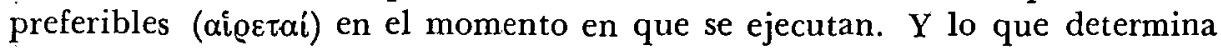
la preferencia no es la indole de las mismas, sino la de la situación en que se encuentra el que las realiza. Por eso escribe el filósofo que "normalmente

\footnotetext{
$18 E N, 1135$ a, 27-28.

$19 E N, 1135$ a, 30-31.

$20 E N, 1135$ b, 2-8.

$21 E N, 1110$ a, $4^{-11}$.
} 
nadie arroja la carga de buen grado", aun cuando, para salvarse de la borrasca, "lo hagan todos los que están en su sano juicio".

Comentando estos pasajes, H. H. Joachim explica de este modo el pensamiento de Aristóteles: el que actúa "tiene el control de sus miembros -mueve sus manos, por ejemplo, al arrojar la carga - de manera que no se trata de un caso de fuerza ( $\beta$ i $\alpha$ ), en el sentido definido en $1109 \mathrm{~b}, 35-1110$ a, 4 . Por tanto, la causa eficiente está en el hombre y, siendo así, de él depende también 'obrar o no' (1110 a, 17-18). A tales acciones tenemos, pues, que llamarlas Ėxov́øı respecto de su circunstancia, aun cuando, sin esta califica-

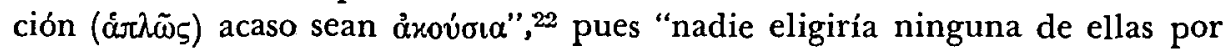
sí misma". ${ }^{23} \mathrm{Si}$ las juzgamos abstractamente, son involuntarias; pero en el caso concreto, es decir, en las circunstancias en que se realizan, son voluntarias. A ello se debe que el Estagirita les dé el calificativo de "mixtas". ${ }^{24}$

\section{Causas determinantes de la involuntariedad de una acción}

En la Ética nicomaquea, Aristóteles menciona dos circunstancias que resultan incompatibles con la voluntariedad de un acto: $a$ ) la de que se realice por ignorancia; $b$ ) la de que se produzca como resultado de una fuerza externa $\left(\beta^{\prime}(\alpha){ }^{25}\right.$ Mas, como Richard Loening lo advierte, lo mismo en la Retórica que en la Ética eudemia y en los Magna Moralia ${ }^{26}$ el preceptor

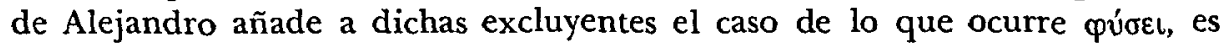
decir, como consecuencia de fenómenos de índole puramente natural.

Los actos del hombre -leemos en la Retórica- o dependen o no dependen de él. De los que no dependen de él, unos se deben al acaso; otros, a la necesidad; $y$, de los últimos, los que no son efecto de la fuerza acaecen por obra de la naturaleza. ${ }^{27}$

La misma tesis es formulada con gran nitidez en la Etica eudemia: objeto de alabanza y censura son la virtud y el vicio y los actos que de una y otro dimanan, pues ni alabamos ni censuramos lo que obedece a la nece-. sidad, o al azar, o a la naturaleza, sino sólo aquello de que nosotros mismos somos la causa. ${ }^{28}$

22 H. H. Joachim, comentario citado, p. 97.

$23 E N, 1110$ a, 19.

24 En torno del concepto aristotélico de acción mixta, H. H. Joachim escribe: En cuan-

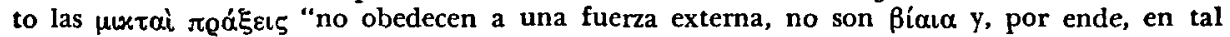

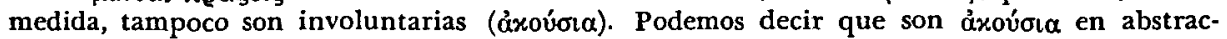
to, pero, en lo que tienen de concreto, es decir, en la situación en que se dan, son Éxoúcı $\alpha$ (voluntarias). $\mathbf{Y}$ como lo único que cuenta sobre los actos es su manifestación concreta - pues toda acción se produce en una situación determinada- debemos considerar a las

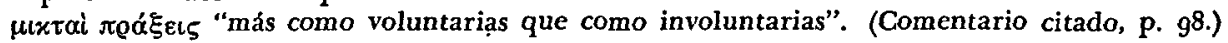

$25 E N$, 1109 b, 35-1110 a, 1.

26 Cfr. Loening, op. cit., p. 186.

27 Ret., 1368 b, 32-36.

$28 E E, 1223$ a, 9-14. 


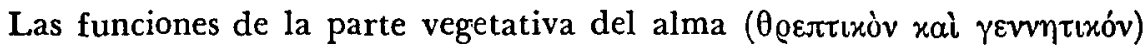
no pueden considerarse como voluntarias ni ser materia de un juicio de valor, porque no son $\varepsilon \dot{\varphi} \varphi^{\prime} \eta \tilde{\mu} \tilde{i}$, es decir, no dependen de nosotros ni su origen reside en representaciones capaces de gravitar sobre nuestra voluntad.29

Tampoco pertenecen a la categoría de lo voluntario las peculiaridades, estados, ventajas, deficiencias o enfermedades del cuerpo, lo que explica que, normalmente, no sean objeto de alabanzas ni de reproches de orden moral. Decimos "normalmente" porque la situación cambia del todo cuando, por ejemplo, alguien se mutila, enferma o deforma por voluntad propia. En estos casos, la causa de la deformación o el morbo está en él, pues de él dependía no haber distorsionado sus miembros o desoído los consejos del médico. Y si, en la misma hipótesis, su proceder se le echa en cara, la censura se justifica, pues él y no otro fue el causante del mal.30

\section{Sobre la necesidad de distinguir entre acciones realizadas "por ignorancia" $y$ "en estado de ignorancia"}

En su monografía sobre la doctrina ąristotélica de la imputación, Richard Loening cita el siguiente pensamiento de Arturo Schopenhauer: "Cuando un hombre quiere, quiere también algo: su acto de voluntad se halla siempre dirigido hacia un objeto, y sólo en relación con éste puede pensarse." 31 Tal objeto tiene, por tanto, que aparecer primeramente en la representación del volente, y dicha representación ( $(\alpha v \tau \alpha \sigma i \alpha)$, sea racional o sensible, da al querer su contenido y constituye, además, su fundamento. ${ }^{32}$ La misma idea - prosigue Loening- existe ya en Aristóteles: nota ulterior de la conducta voluntaria, de lo Éxoúoıv, es, para el Estagirita, que el actuante "obre a sabiendas" o, como se dice en griego, zió́s.

Surge así este problema: ¿las acciones queridas por nosotros son Éxov́ola sólo cuando la representación y la voluntad coinciden con lo que objetivamente acaece? $O$, en otras palabras: ¿es necesario, para que una conducta sea imputable, un saber referido al resultado?... El que ejecuta un acto

$29 E N, 1144 \mathrm{~b}, 1-17 ; E E, 1215$ a, 14-20. Cfr. Loening, op. cit., pp. 187-18g.

30 "Al injusto y al licencioso - escribe Aristóteles- les era posible, en un principio, no haber llegado a ser tales, razón por la cual lo son voluntariamente. Pero, habiendo llegado a serlo, les resulta imposible no serlo ya. Y no sólo los vicios del alma son voluntarios, sino que, en algunos hombres, también lo son los del cuerpo, y por ello los censu. ramos. Nadie censura a los deformes por naturaleza, pero sí, en cambio, a quienes lo son por falta de ejercicio y por descuido. De modo semejante ocurre respecto de la debilidad y la invalidez: pues nadie le haria reproches al ciego de nacimiento o por enfermedad o accidente, sino que más bien le tendría lástima; todo el mundo, en cambio, censura al que perdió la vista por su afición al vino o por cualquiera otro desorden." EN, 1114 a, 21-g1.

31 Schopenhauer, Die beiden Grundprobleme der Ethik (Los dos problemas fundamentales de la ética), 2. Aufl., p. 14. Cita de Loening en la p. 168 de su obra.

32 Loening, op. cit., p. 168. 
puede, en efecto, tener conciencia de lo que hace y saber en vista de qué lo hace, pese a lo cual el resultado escapa por completo a su previsión. Por ejemplo: desea mostrar a otro el funcionamiento de una catapulta, pero la máquina accidentalmente se dispara y da muerte a un hombre. ${ }^{33}$

El saber exigido por el concepto de lo voluntario debe referirse a las circunstancias de la acción y, especialmente, "a las principales", esto es, "al qué y al para qué de ésta".34 Quien, respecto de alguna de ellas (ya que sería imposible conocerlas todas), está en un error o se las representa falsamente, no obra de acuerdo con lo que en verdad quiere o, dicho de otra

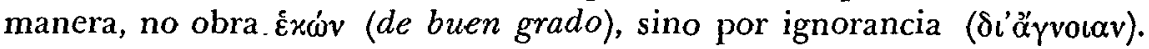

¿Qué especie de ignorancia - pregunta Joachim- hace que un proceder pertenezca a la categoría de lo involuntario?... El comentarista inglés resume en estos términos la respuesta de Aristóteles: “a) Ninguna acción rea-

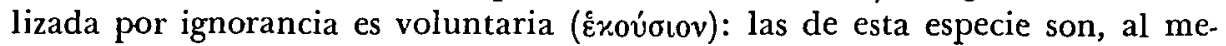

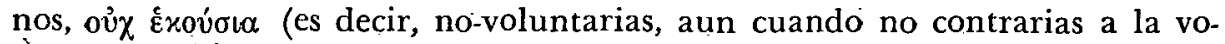
luntad), si el agente puede en conciencia decir: 'De haberlo sabido, no lo habría hecho', o sea, si se siente molesto y arrepentido al descubrir lo que hizo $(E N, 1110 \mathrm{~b}, 18-24)$; b) el acto que se ejecuta por ignorancia debe ser distinguido del que se realiza en estado de ignorancia. Obrar en tal estado no excusa al actuante, aun cuando, al cobrar conciencia de lo que hizo, se arrepienta de haberlo hecho. Por ejemplo: un ebrio puede cometer un asesinato en estado de ignorancia, pero a consecuencia de haber bebido. c) Cabría decir que todos los criminales cometen sus fechorias en semejante estado, esto es, ignorando lo que realmente es bueno para ellos o, en otras palabras, el fin y el plan de vida correctos. Es ésta una ignorancia del principio universal de la conducta, o ignorancia del propósito. A ella atribuía Sócrates toda mala acción, pero el corolario de su doctrina era: 'Consecuentemente, tal ignorancia nos hace merecedores de censura'," 35

Resumiendo podemos decir que, de acuerdo con Aristóteles, a los actos humanos no les son aplicables los predicados bueno y malo cuando les falta, total o parcialmente, la nota de la voluntariedad ${ }^{\mathbf{3 6}} \mathrm{o}$, expresado de otra manera, cuando no han sido ejecutados en forma consciente ni han sido queridos.

$33 E N, 1111$ a, 8-11.

$34 E N, 1111 \mathrm{a}, 15-19$. Otros ejemplos en $M M, 1188 \mathrm{~b}, 3^{1-35} ; E E, 1225 \mathrm{~b}, 1-10$. Sobre el caso del filtro de amor, a que se hace referencia en $M M, 1188 \mathrm{~b}, 31-35$, véase la explicación de Loening en la nota 4 de la p. 211 de su monografía.

35 H. H. Joachim, comentario citado, p. 99. Según Loening, el verdadero sentido de

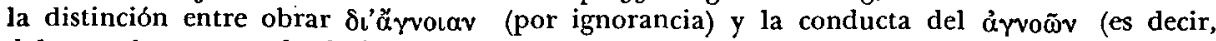
del que obra en estado de ignorancia), consiste en que, en el primer caso, el actuante tiene plena conciencia y sólo ignora o juzga en forma incorrecta determinadas peculiaridades de su circunstancia, en tanto que, en el otro caso, el sujeto se halla en un estado de grave perturbación de sus facultades (embriaguez total o ira ciega, por ejemplo). Loening, op. cit., p. 218.

36 Cfr.: Loening, op. cit., p. 210. 
Las acciones involuntarias (áxoúola) no.son obra nuestra, no dependen de nosotros, y el hombre que en el caso ejecuta el movimiento corporal que produce un resultado nocivo no es, según el autor de la Ética nicomaquea, "causante" ni, por ende, "responsable" de aquéllas.37 Los actos de tal clase no son objeto de alabanza o censura respecto del actuante; "éste es más bien (cuando el hecho es injusto de acuerdo con su forma externa o el efecto no

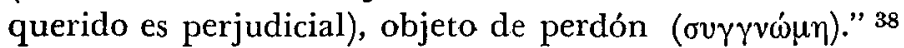

En el capítulo octavo del Libro $V$ de la misma obra, el Estagirita sostiene que los daños que los hombres provocan respecto de sus congéneres al relacionarse de algún modo con ellos, son de tres clases. A la primera pertenecen los que se causan por ignorancia, y deben llamarse errores "cuando, supongamos, alguien obra con desconocimiento de la persona, del acto, del instrumento y del motivo; pues, por ejemplo, o no se quiso herir, o no con tal instrumento, o no a tal persona, o no con tal fin. Sino que, sobrevenido el daño, no se pensó en el resultado: como cuando se realizó la acción no para herir, sino para pinchar, o se hirió no al que se pretendía, o no con el mismo instrumento". 39 Las circunstancias particulares que el Estagirita toma en cuenta al clasificar los daños pueden, pues, referirse: 1) a la persona danada; 2) a la naturaleza del acto dañino; 3) al instrumento con que se daña; 4) al propósito del actuante.

Respecto de la última circunstancia, Aristóteles introduce una distinción

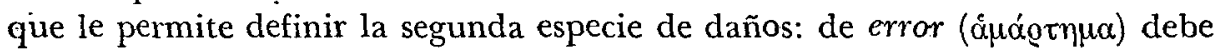
hablarse solamente cuando el daño no ocurre fuera de lo previsto, pero el que lo ocasiona procede sin maldad.40 $\mathrm{Si}$, por el contrario, el daño ocurre fuera de lo previsto, el acto que lo ocasiona no es un error, sino un infortunio $(a ̊ x u ́ \chi \eta \mu \alpha)$. Este último carácter es precisado así por Aristóteles: “Un hombre yerra cuando el principio de la ignorancia está en él; es, en cambio, infortunado, cuando ese principio le es ajeno." 41

Los daños del tercer grupo son los producidos por quien obra "a sabiendas". Respecto de los de esta clase, el Estagirita establece una distinción. Si alguien obra "a sabiendas, mas sin deliberación previa, la acción es injusta, como cuando sucede por cólera y otras pasiones que afectan a los hu-

37 Loening, op. cit., pp. 172 ss. Cfr.: Aristóteles, $E N, 1113 \mathrm{~b}, 17^{-21}$ :

$38 E N, 1110 \mathrm{~b}, 30-35 ;$ Ret., 1373 a, 28-29. Según Loening, el perdón de que habla Aristóteles no tiene el sentido moderno de gracia (Begnadigung), aun cuando el Estagirita también emplee la palabra en tal acepción; su significado es más bien, como se expresa en $E N, 1143$ a, 19, la de un juicio que "más allá de la rígida letra de la ley abstracta, toma en cuenta las situaciones concretas y la verdadera naturaleza del hecho singular". Trátase, en otras palabras, de una actitud que, frente a la legalidad puramente formal, hace valer la justicia material y la equidad, para juzgar del hecho como lo haría el varón equitativo" (Loening, op. cit., p. 185).

39 $E N, 1135 \mathrm{~b}, 11-16$.

$40 E N, 1135$ b, $16-19$.

41 Idem. 
manos en forma necesaria y general. Pues, dañando y errando en estos casos, proceden injustamente, y sus actos son injusticias. Sin embargo, no por ello llegan a ser injustos, ni malvados tampoco, puesto que el daño no se causa por perversidad. Pero si hubo elección previa, entonces se es injusto y perverso. Por ello, las acciones que nacen de la cólera certeramente se juzgan como no resultantes de una previa reflexión. Pues causa de las mismas no es el que obra con cólera, sino el que lo encolerizó".42

Son igualmente involuntarias aquellas conductas, contrarias al nómos, respecto de las cuales el actuante ignora la circunstancia condicionante de su ilicitud, o cree en la existencia de un hecho que tornaria licita la acción. Por ejemplo: no es adúltero quien, sin percatarse de ello, tiene contacto sexual con una mujer que no es la suya; ${ }^{43}$ ni hay asesinato cuando, en una batalla, uno de los combatientes da muerte a su propio padre, creyendo que era un enemigo; ${ }^{44}$ ni existe perjurio cuando un hombre jura algo sin saber que lo que afirma es falso.45

\section{Concepto de "elección previa"}

Al estudiar Aristóteles la tercera especie de daños, y sostener que son los causados cuando el actuante "obra a sabiendas", distingue, respecto de los mismos, dos series de casos: aquellos en que hubo y aquellos en que no hubo elección previa. Veamos en qué forma este concepto es definido por el filósofo.

Después de subrayar que la elección previa "se halla en la más íntima conexión con la virtud", pues, más que los actos, "permite juzgar los caracteres", 46 nos previene contra el peligro de confundirla con lo voluntario.

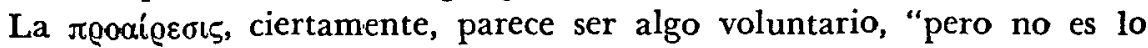
mismo, sino que lo voluntario tiene mayor extensión", 47 pues de lo voluntario "participan también los niños y todos los animales, mas no de la previa elección". ${ }^{48}$ Además, a los actos repentinos los declaramos Érov́oıa, pese a su índole no reflexiva.

$42 E N, 1135 \mathrm{~b}, 19-27$. La doctrina aristotélica sobre los daños en las relaciones interhumanas puede, pues, resumirse asf:

Daños en las relaciones interhumanas.

$43 E E ., 1221 \mathrm{~b}, 23-25$.

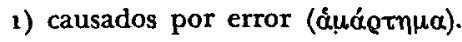

2) resultantes de un infortunio

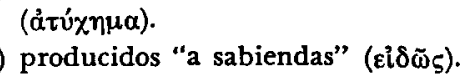
$\left\{\begin{array}{l}\text { a) sin deliberación } \\ \text { previa. } \\ \text { b) previa deliberación. }\end{array}\right.$

45 Ret., 1977 b, 4-6.

$46 E N, 1111 \mathrm{~b}, 5^{-6}$.

$47 E N, 1111 \mathrm{~b}, 6-8$.

$48 E N, 1111 \mathrm{~b}, 8 \cdot 9$. 


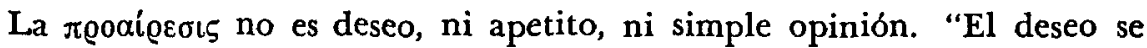
refiere a lo placentero y a lo aflictivo, mientras que la elección previa no

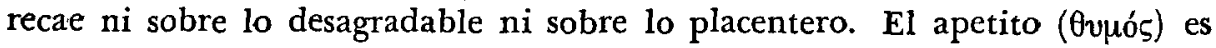
todavía inferior, pues los actos que engendra son los que menos parecen provenir de una elección previa. Ésta tampoco es deseo volitivo (ßoúînot5), aun cuando sea algo que parece muy conexo." Sería insensato quien, tratándose de cosas imposibles, dijese haberlas elegido previamente. El deseo volitivo de lo imposible puede, en cambio, existir, respecto de la inmortalidad, por ejemplo. Es concebible, también, que alguien desee lo que él, por sí mismo, de ningún modo podría ejecutar, como, verbigracia, que su atleta favorito triunfe en los juegos. ${ }^{50}$

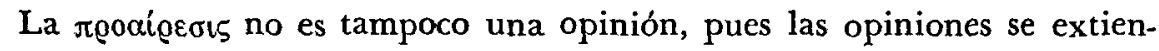
den a todas las cosas, lo mismo a lo eterno y a lo imposible que a lo que está en nuestra mano. Además, de aquéllas se afirma que son verdaderas o falsas, en tanto que de una elección no se dice que sea falsa o verdadera, sino buena o mala. Por otra parte, la elección es alabada cuando recae sobre lo que debe hacerse, en tanto que las opiniones sólo merecen elogios cuando son verdaderas. ${ }^{51}$

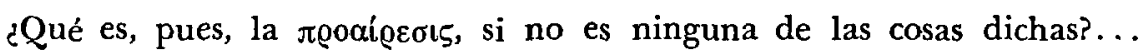
¿Será, acaso, lo predeliberado?...

Antes de responder conviene tomar en cuenta que hay cosas respecto de las cuales deliberar es imposible. Nadie delibera acerca de lo eterno, ni relativamente a lo que siempre ocurre de acuerdo con las mismas leyes, "sea por naturaleza o por cualquiera otra causa, como, por ejemplo, los solsticios y las salidas del sol". ${ }^{52}$ Tampoco deliberamos sobre lo que sólo es obra de la suerte, el hallazgo de un tesoro, verbigracia.53

La deliberación (ßov́l£voıs, en griego) sólo puede referirse, según los precedentes ejemplos, a las cosas que nosotros mismos podemos hacer y que, por tanto, pertenecen a la esfera de lo contingente y lo indeterminado.54 Pero "no recae sobre los fines, sino sobre los medios que a ellos conducen. No delibera el médico si curará, ni el orador si persuadirá, ni el político si creará una buena legislación, ni delibera ninguno de los demás respecto del fin, sino que, habiéndose propuesto una finalidad, examinan de qué modo y en virtud de qué medios será alcanzada, y si parece alcanzarse en virtud de muchos, inquieren por cuál de ellos lo será más fácil y convenientemente; pero si sólo es realizable por un medio, preguntan cómo puede lograrse, y

$49 E N, 1111 \mathrm{~b}, 16-20$.

50 EN, 1111 b, 20-24.

ธ1 $E N, 1111 \mathrm{~b}, 30-34$.

$52 E N, 1112$ a, $21-26$.

$53 E N, 1112 \mathrm{a}, 27$.

$54 E N, 1112$ a, 30-31; 1112 b, 10-11. Cfr. H. H. Joachim, comentario citado, pp. 101-102. 
el medio por cuál, hasta llegar al primer determinante, que en la fase del descubrimiento es lo último".55

El aserto de que la deliberación no recae sobre los fines, sino sobre los medios, plantea un problema, ya que, de acuerdo con la doctrina aristotélica sobre la estructura teleológica de la conducta humana, los fines que tienen, a la vez, el carácter de medios (relativamente a fines más altos), en cuanto medios serían, y en cuanto fines no serían objeto de deliberación. Sólo respecto del fin último no existiría el escollo, porque ese fin no puede asumir carácter medial.

La dificultad desaparece si se tiene en cuenta, como Aubenque lo subra-

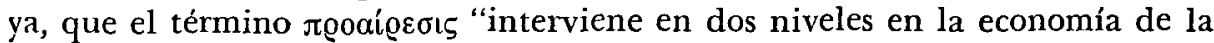
ética de Aristóteles. Una primera vez entra en la definición de la virtud moral, que en el Libro II de la Ética nicomaquea es caracterizada como

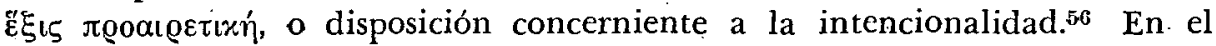
Libro III, el término aparece en un contexto enteramente diverso, el relativo al análisis general de la estructura de la acción: y es aquí donde figura con el significado de elección predeliberada". ${ }^{57}$ Por eso, cuando el filósofo

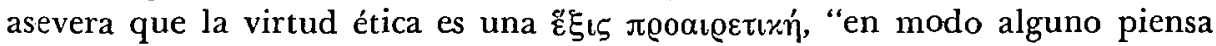
en el análisis que de la elección deliberada hará en el Libro III de la Ética nicomaquea". Lo que pretende decir es que en la virtud se exterioriza una decisión que proviene de nosotros mismos y que, como tal, condiciona nues-

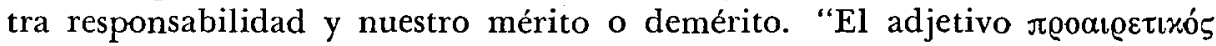
indica la diferencia específica que separa a la virtud moral, única imputable, de la virtud natural, cuya posesión no engendra mérito ninguno, puesto que no atañe a nuestra proáiresis." 58

No se olvide que, incluso en el citado Libro III, Aristóteles declara que "el deseo volitivo se refiere más bien al fin, en tanto que la elección previa recae sobre las cosas conducentes al fin. Por ejemplo, deseamos estar sanos, pero elegimos previamente aquello gracias a lo cual conservamos la salud. Deseamos, igualmente, ser felices, pero sería inadecuado afirmar que lo elegimos de antemano".59 Cuando el Estagirita escribe que "el médico no delibera si curará, ni el orador si persuadirá, ni el político si creará una buena legislación", naturalmente $d a$ por supuesto que tanto el médico, como èl orador, como el político, desean el fin propio de las artes que profesan, por considerarlo intrínsecamente valioso. La elección, en su sentido ético (no en el técnico), debe referirse, como dice $\mathrm{D}$. J. Allan, al proceso total que consiste "en formular reglas para la acción y en aplicarlas intuitivamente a

$55 E N, 1112$ b, $11-20$.

56 Pierre Aubenque, La prudence chez Aristote, Presses Universitaires de France, Paris, 1963 , p. 119 .

57 Idem.

58 Idem.

$59 E N, 1111 \mathrm{~b}, 26-29$. 
tales o cuales circunstancias particulares. Pero, preferir un acto porque constituye una instancia de un buen principio que deseamos realizar de la mejor manera posible en nuestras vidas, no es lo mismo que seleccionarlo porque pensamos que conducirá a un fin bueno".60 En el primer caso, el acto, oriundo de una intención moralmente recta, vale por sí mismo; en el segundo, en cambio, su valor depende del resultado obtenido. "En los libros sexto y séptimo de la Ética nicomaquea - prosigue Allan- la elección es presentada y analizada, casi exclusivamente, desde el primer punto de vista. $Y$, entonces, el aserto de que la elección que un hombre hace es mejor prueba de su carácter que sus actos, ${ }^{61}$ deja de parecernos no razonable. Pues es verdad que sus sólidas reglas y principios de acción son la prueba decisiva de su carácter." 2

Volviendo a los ejemplos podría admitirse que, cuando un joven se pregunta a qué actividad profesional dedicará su vida, y pondera, teniendo en cuenta sus aptitudes y limitaciones, las ventajas y los inconvenientes que una u otra de esas actividades tendría para él, las últimas aparecen ante sus ojos como posibles medios o caminos al servicio de ese supremo fin que es la eudemonia, razón por la cual, respecto de tales medios, delibera. Pero cuando, definida su vocación, decide, pongamos por caso, convertirse en médico, la finalidad del arte a que desea consagrarse no es ya deliberable. $\mathrm{Y}$ es que, por definición, el fin de la medicina es curar, como el de la estrategia es vencer y el de la oratoria persuadir. Cuando se elige cualquiera de ellas, el fin de la misma deriva de la naturaleza de la actividad escogida, y lo único deliberable, respecto del ejercicio de cada profesión, son los medios que quien la practica ha de emplear para el logro de ese fin dado previamente.

Si ahora nos preguntamos por la diferencia entre lo deliberable y lo preelegible llegaremos a la conclusión de que "son lo mismo, salvo que lo que se elige ya está determinado". 63 Podemos, pues, decir: "Siendo lo preelegido lo deseado, previa deliberación, de entre las cosas que de nosotros dependen, la elección previa sería el deseo deliberativo de lo que en nuestra mano está. Pues juzgando una vez que se ha deliberado, tendemos a lo apetecido de acuerdo con la deliberación." 64

"Si el hombre es el origen y el padre de sus actos, como lo es de sus hijos", ${ }^{6}$ el mérito o el demérito que de éstos provienen sólo podrán ser refe-

60 D. J. Allan, The Philosophy of Aristotle. London, Oxford University Press, New York-Toronto, 1957, p. 177. En el mismo sentido: Joseph Moreau, Aristote et son école, Presses Universitaires de France, Paris, 1962, pp. 216 y 217.

$61 E N, 1111 \mathrm{~b}, 5^{-6}$.

62 Allan, op. cit., p. 177.

as $E N, 1113$ a, 2-4.

64 EN, 1113 a, 9-12.

$65 E N, 1113$ b, $17-18$. 
ridos al sujeto en quien tal origen reside. Mas lo que de los actos decimos debe igualmente afirmarse de las virtudes y los vicios. "De nosotros, precisamente, depende la virtud y, del mismo modo también, la maldad. Pues en las cosas que de nosotros dependen está el obrar, y donde está el no, está también el sí. De manera que, si de nosotros depende hacer lo que es bueno, de nosotros dependerá no hacer lo que es vergonzoso. $Y$ si no hacer lo que es bueno depende de nosotros, hacer lo que es vergonzoso dependerá igualmente de nosotros." 66

Por eso, concluye Aristóteles, los legisladores sancionan a los que hacen cosas malas, salvo que las hagan bajo coacción "o por ignorancia de la que no sean responsables"; ${ }^{67} \mathrm{y}$, a la inversa, a quienes realizan actos buenos los premian, "cual si quisieran estimular a los unos y refrenar a los otros". ${ }^{68}$ Castigan, igualmente, "por el ignorar mismo", cuando el que ignora es culpable de su ignorancia. Por ejemplo: a los que delinquen en estado de ebriedad les imponen una pena doble, ya que "eran dueños de no haberse embriagado, y la embriaguez fue causa de su ignorancia". Castigan, también, la ignorancia de las leyes, cuando conocerlas no era difícil, que las cosas que los hombres parecen ignorar por negligencia, "ya que el no ignorarlas dependía de ellos y en su mano estaba haber tenido cuidado".70

INSTITUTO DE INVESTIGaciones FiLosóficas

Eduardo García Máynez Universidad Nacional Autónoma de México

$66 E N, 1113$ b, 6-11. Sobre la imputación de omisiones, véanse los interesantes desarrollos de Richard Loening en la sección 15, pp. 245 ss., de su tantas veces citada obra.

$67 E N, 1113 \mathrm{~b}, 23-25$.

$68 E N, 1113 \mathrm{~b}, 25-26$.

$69 E N, 1113$ b, 33-1114 a, 1 .

70 EN, 1114 a, 1-2. 